\title{
Distribution and Abundance of Antibiotic Resistance Genes in Sand Settling Reservoirs and Drinking Water Treatment Plants across the Yellow River, China
}

\author{
Junying Lu ${ }^{1,2}$, Zhe Tian ${ }^{1,2}$, Jianwei Yu ${ }^{1,2}$, Min Yang ${ }^{1,2}$ and Yu Zhang ${ }^{1,2, *(D)}$ \\ 1 State Key Laboratory of Environmental Aquatic Chemistry, Research Center for Eco-Environmental Sciences, \\ Chinese Academy of Sciences, Beijing 100085, China; junying.lu.cn@gmail.com (J.L.); \\ zhetian@rcees.ac.cn (Z.T.); jwyu@rcees.ac.cn (J.Y.); yangmin@rcees.ac.cn (M.Y.) \\ 2 University of Chinese Academy of Sciences, Beijing 100049, China \\ * Correspondence: zhangyu@rcees.ac.cn; Tel.: +86-010-6291-9883
}

Received: 17 January 2018; Accepted: 23 February 2018; Published: 28 February 2018

\begin{abstract}
Understanding how antibiotic resistance genes (ARGs) are distributed in drinking water treatment processes is important due to their potential public health risk. Little is known about the occurrence and distribution of ARGs in typical drinking water treatment processes, such as sand settling reservoirs (SSRs) and drinking water treatment plants (DWTPs), in the Yellow River, especially at the catchment scale. In this study, ARG profiling was investigated from water samples of influent (river water) and effluent (source water) of SSRs and finished water of DWTPs in six cities along the Yellow River catchment using real-time quantitative polymerase chain reaction (qPCR) and 16S rRNA gene sequencing. Seventeen ARGs and two mobile genetic elements (MGEs) were detected, among which aadE, strA, strB, tet $A$, sulII, intl1, and Tn916 had high detection rates (over $80 \%$ ). The absolute abundances (gene copies/mL of water) of ARGs were reduced by the SSRs and DWTPs generally, but no reductions were observed for the relative abundances (gene copies/16S rRNA gene) of ARGs. Spatial distributions of ARGs and bacteria were not observed. The distribution of bacterial genera was clustered into four dominant patterns in different water type samples. The bacterial genera Pseudomonas, Massilia, Acinetobacter, Sphingomonas, Methylobacterium, and Brevundimonas dominated the finished water, with Brevundimonas and Methylobacterium being speculated to be potential hosts for two ARGs (strA and strB) through network analysis. The enrichment of these two genera, likely caused by selection of disinfection process, may contribute to the higher relative abundance of ARGs in finished water. This study provides insight and effective assessment of the potential risk of ARGs in drinking water treatment processes at the catchment scale.
\end{abstract}

Keywords: antibiotic resistance gene; sand settling reservoirs; drinking water treatment plants; the Yellow River

\section{Introduction}

Antibiotic resistance genes (ARGs), as emerging environmental pollutants [1], are a major concern associated with the spread and development of antibiotic resistance. The aquatic environment is recognized as one of the most important reservoirs for antibiotic resistant bacteria (ARB) and ARGs [2,3]. With the wide use of antibiotics in human and veterinary medicine and the agricultural industry, ARGs have been detected in a variety of environments, including surface river water [1], municipal wastewater treatment plants (MWTPs) [4], drinking water treatment plants (DWTPs) [5], and water supply reservoirs [6]. Notably, growing evidence shows the existence of ARB and ARGs in drinking water systems from source water to finished water [5,7-10]. Since finished water from DWTPs is provided to local populations, the prevalence of ARGs in drinking water systems can be a potential threat to public health. 
Previous studies have reported wide distribution of ARB and ARGs in source water, which gives resistance to a variety of antibiotics, including resistance to beta-lactams, aminoglycosides, fluoroquinolone, sulfonamide, tetracycline, and cephalosporin [6,9,11-14]. Many earlier studies have focused on the occurrence and quantity of ARGs in DWTPs [5,8,15-18]. Previous quantification of ARGs (including cat, cmr, bla $a_{\mathrm{TEM}}, b l a_{\mathrm{SHV}}$, sulI, sulII, tet $\mathrm{W}$, and tetO) in DWTPs and distribution systems showed that the absolute abundance of ARGs (gene copies/water volume) was lower in finished water than source water, though relative abundance (normalized to 16S rRNA gene) exhibited no obvious variation [15]. To gain insight into the mechanism of ARG variation in DWTPs, studies have examined the proceeding treatment processes. In DWTPs in the Yangtze River Delta, sulfonamide and tetracycline resistance genes were found to be more abundant after treatment with biological activated carbon (BAC) [8]. Among treatment processes, chlorine is believed to enrich the proportion of ARB and the relative abundance of ARGs due to the co-selection of resistance bacteria $[5,7,8,17]$, indicating that ARGs may be enriched after DWTP treatment. Current studies have primarily focused on specific or scattered DWTPs, and thus further representative research on ARGs in DWTPs at the catchment scale is needed.

The Yellow River is one of the most important water sources in northern China, with many cities along its banks and watershed that are using it for drinking water. As the river water has high turbidity, sand settling reservoirs (SSRs) have been built for pretreatment in many cities. Previous studies on the Yellow River Catchment show the prevalence of a variety of antibiotics, with concentrations of antibiotics in the river ( 25 to $152 \mathrm{ng} / \mathrm{L}$ ) and sediment (up to $184 \mathrm{ng} / \mathrm{g}$ ) being greater than in rivers in Europe $[19,20]$. However, the pollution levels of ARGs in the Yellow River remain underreported, and little is known about the occurrence and distribution of ARGs in drinking water treatment processes such as SSRs.

This study aimed to elucidate the distribution and abundance of ARGs in SSRs and DWTPs at the catchment scale, and to reveal the relationships and effects between ARGs and their potential hosts in the treatment processes. Real-time quantitative polymerase chain reaction (qPCR) was used to document the prevalence of 17 ARGs and two mobile genetic elements (MGEs) (intl1 and transposon Tn916) in river water (influent of SSRs), source water (effluent of SSRs), and finished water (effluent of DWTPs) of six cities (Lanzhou, Yinchuan, Hohhot, Zhengzhou, Jinan, and Dongying) in the Yellow River catchment in China. Target ARGs included five aminoglycoside ARGs, five macrolide ARGs, six tetracycline ARGs, and one sulfonamide ARG. The selection of ARGs were based on those identified in previous studies and our preliminary detection experiment. Among all the ARGs observed in the drinking water source and drinking water treatment plants, tetracycline and sulfonamide ARGs were most common $[8,12,18,21]$, followed by macrolide, aminoglycoside and other ARGs $[5,9]$. Using Illumina MiSeq sequencing, the bacterial community structures in the drinking water treatment processes were characterized. Additionally, the co-occurrence patterns between ARGs and bacterial taxa were also analyzed by network analysis. The results of this study will provide information and insight for understanding the prevalence and propagation of ARGs in SSRs and DWTPs, as well as their correlations with bacteria, which should be useful for their management.

\section{Materials and Methods}

\subsection{Study Sites and Sampling}

Sampling was conducted in the winter from February to March 2014. Six cities along the Yellow River, including Lanzhou (LZ), Yinchuan (YC), Hohhot (HS), Zhengzhou (ZZ), Jinan (JN), and Dongying (DY), were selected for this study (Figure 1a). It should be noted that the sampling time is in winter with less rainfall and lower water flow, and there would be different results in summer, which need further studies in the future. Except for Lanzhou, each city has a SSR to reduce the high turbidity of the river water. All of the DWTPs consist of conventional drinking water treatment processes (coagulation and sedimentation, sand filtration, chloramine disinfection), except BAC filter was used in Jinan 
DWTP. River water and source water samples were taken from the influent and effluent of the SSRs at $0-0.5 \mathrm{~m}$ depth below the water surface. The river water sample from Lanzhou was taken directly from the influent of DWTP. Finished water samples were taken from the effluent of DWTPs (Figure 1b). Triplicate samples were collected in 500-mL pre-cleaned and sterilized glass bottles, where the bottles were washed and rinsed by pure water from Millipore purification system and sampling water. A total of 15 samples were stored in thermotanks with ice bags and were delivered to the laboratory as soon as possible. Typical water quality parameters of the source water were tested, as shown in our previous study [22] and summarized in Table S1.

a

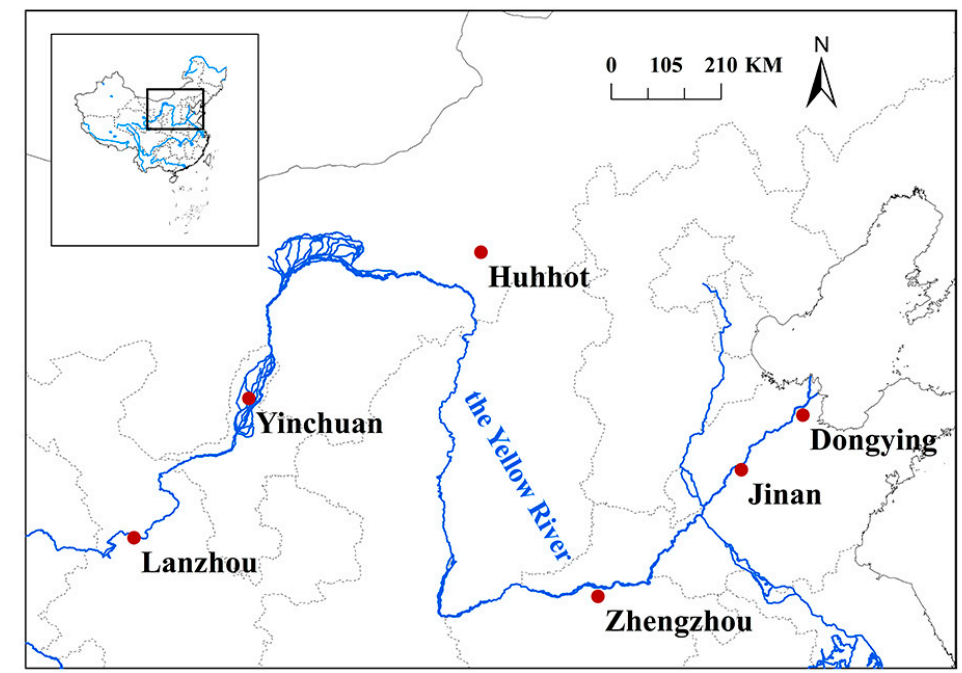

b

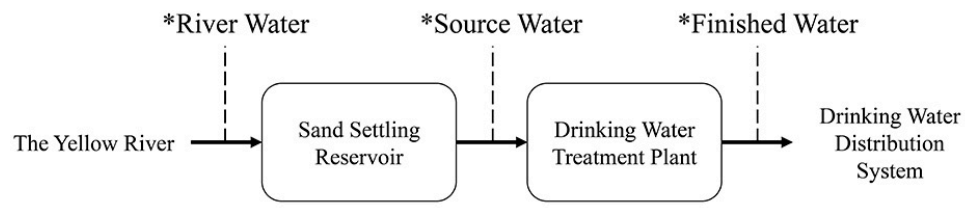

Figure 1. (a) Sampling locations (Lanzhou, Yinchuan, Hohhot, Zhengzhou, Jinan, Dongying); (b) Drinking water treatment processes, including sand settling reservoir and drinking water treatment. "**": Sampling sites.

\subsection{DNA Extraction}

Water samples were filtered through $0.22-\mu \mathrm{m}$ mixed cellulose ester membrane filters (Millipore, Australia) to capture bacteria. The membrane filters were stored at $-20^{\circ} \mathrm{C}$ in 2 -mL centrifuge tubes until DNA extraction. The DNA was extracted from the membranes using a FastDNA SPIN Kit (MP Bio, Solon, OH, USA) according to the manufacturer's instructions. The concentration of the purified DNA was quantified spectrophotometrically (NanoDrop ND-1000, Thermo, Waltham, MA, USA), with the purified DNA then stored at $-20^{\circ} \mathrm{C}$ until subsequent analysis and qPCR assays were performed.

\subsection{Real-Time $q P C R$}

Five aminoglycoside ARGs ( $a a d B, a a d E, a p h A 1, \operatorname{str} A$, and $\operatorname{str} B)$, five macrolide ARGs (ere $A$, ermF, erm $G$, erm $X$, and mefA), six tetracycline ARGs (tet $A$, tet $G$, tet $O$, tet $Q$ tet $W$, tet $X$ ), one sulfonamide ARG (sulII), two MGEs (intl1 and transposon Tn916), and the 16S rRNA gene were quantified using SYBR-Green real-time qPCR. The primer sequences and PCR conditions were verified in recently published papers and in this study [23] (Table S2). Positive controls contained cloned and sequenced PCR amplicons that were obtained from the sludge of wastewater treatment plants in our previous study [23]. Concentrations of the standard plasmids $(\mathrm{ng} / \mu \mathrm{L})$ were determined with the NanoDrop ND-1000, and their copy concentrations (copies/ $\mu \mathrm{L}$ ) were then calculated [24]. 
The $25-\mu \mathrm{L}$ reactions of qPCR typically contained $1 \times$ SYBR Green I, $1 \times$ Dye $(\mathrm{TaKaRa}), 200 \mathrm{nM}$ of each primer, $0.5 \mathrm{mg} / \mathrm{mL}$ BSA, and $2 \mu \mathrm{L}$ of DNA templates. Real-time PCR was run using an ABI 7300 system (ABI, Foster City, CA, USA) with the following program: $95^{\circ} \mathrm{C}$ for $30 \mathrm{~s}, 40$ cycles consisting of: (i) $95{ }^{\circ} \mathrm{C}$ for $10 \mathrm{~s}$; (ii) annealing temperature for $15 \mathrm{~s}$; (iii) $72{ }^{\circ} \mathrm{C}$ for $15 \mathrm{~s}$; and (iv) $78{ }^{\circ} \mathrm{C}$ for $26 \mathrm{~s}$ to collect the fluorescent signals. The melting process was automatically generated using the ABI 7300 software. Ten-fold dilution of plasmids carrying the target gene were used as calibration standards, ranging from $10^{8}$ copies to $10^{2}$ copies. Standard curves were constructed in each PCR run and the copy numbers of genes in each sample were interpolated using these standard curves. All of the standards, samples, and negative control (sterile water) were quantified in triplicate.

Reliable correlation coefficients $\left(R^{2}>0.99\right)$ for standard curves over five orders of magnitude were obtained. Amplification efficiencies based on slopes were between $85.39 \%$ and $112.75 \%$ (Table S3). The detection limits were between $1.4 \times 10$ to $2.86 \times 10^{3}$ copies per $\mu \mathrm{L}$ added DNA, as shown in Table S3. Only samples in which two of the three replicates were above the limits were regarded as positive. Specificity was ensured by melting curves and gel electrophoresis. The copy number of the target gene was calculated based on the calibration curves. Relative abundances of the ARGs and MGEs were normalized to bacterial 16S rRNA genes for comparison. Absolute abundance was calculated based on number of gene copies per the water sample volume $(\mathrm{mL})$. The removal of ARGs was calculated as log removal [25]. Removal of ARGs in selected treatment process $=\log \mathrm{X}-\log \mathrm{Y}$. X and $\mathrm{Y}$ are total absolute abundance of ARGs in influent and effluent of selected treatment process.

\subsection{Illumina MiSeq Sequencing for $16 S$ rRNA Gene}

The DNA samples were diluted to $10 \mathrm{ng} / \mu \mathrm{L}$, with $20 \mu \mathrm{L}$ of each sample sent to a commercial laboratory (Majorbio, Beijing, China) for Illumina MiSeq sequencing. Samples were sequenced following the manufacturer's guidelines using the Illumina MiSeq sequencing instruments and reagents by paired-end strategy. The specific primers (515F: GTGCCAGCMGCCGCGGTAA, and 806R: GGACTACHVGGGTWTCTAAT) were applied for the amplification of V4 region of the 16S rRNA gene [26]. AxyPrepDNA Gel Kit was used to extract the PCR products, then the library construction and sequencing was conducted on the Illumina MiSeq platform. The raw FASTQ data were filtered using QIIME (version 1.17) with following criteria: (i) The reads were truncated that obtained an average quality score of $<20$ over a 50 -bp sliding window, and the truncated reads shorter than $50 \mathrm{bp}$ were discarded; (ii) exact barcode matching, two nucleotide mismatch in primer matching, and reads containing ambiguous characters were removed; and, (iii) only overlapping sequences longer than $10 \mathrm{bp}$ were assembled according to their overlapped sequence. Operational taxonomic units (OTUs) with 97\% similarity cutoff were clustered using UPARSE (version 7.1), and anomalies were eliminated using UCHIME. After filtering for quality, the sequences were aligned against the 16S rRNA sequences in the Silva database (Release119 http:/ / www.arb-silva.de) with OTUs data to identify species at different levels. The rarefaction analysis based on Mothur v.1.21.1 was conducted to reveal the diversity indices. Raw sequencing data were deposited in the NCBI Sequence Read Archive with accession nos. SRR4253864 to SRR4253864.

\subsection{Network Analysis}

Network analysis was used to explore the underlying associations among genes and microbial taxa $[23,27]$. To visualize the correlations between ARGs and bacterial taxa, we constructed a co-occurrence network among the 17 ARGs and two MGEs quantified by qPCR and the 464 bacterial genera that were identified by MiSeq sequencing with the random matrix theory-based network inference method of the 17 water samples [28]. Briefly, all of the possible pairwise Pearson correlations among the 483 items, including the 17 ARGs, two MGEs, and 464 bacterial genera, that occurred in at least nine samples were calculated to construct a correlation matrix [28,29]. Network analyses were performed using an online analysis pipeline at http:/ /ieg2.ou.edu/MENA. Network visualization was conducted on the interactive platform of Gephi (version 0.9.1). 


\subsection{Statistical Analysis}

Correlations among ARGs and MGEs were evaluated by Pearson's bivariate correlation analysis (SPSS 20.0, IBM, Armonk, NY, USA). One-way ANOVA were performed to evaluate the significance of differences among the samples. Heatmap and principal coordinate analysis (PCoA) were performed in R environment using pheatmap [30] and VEGAN [31].

\section{Results and Discussion}

\subsection{Distribution of ARGs in Water Treatment Processes}

The concentrations of the 17 ARGs, two MGEs, and 16S rRNA gene quantified by qPCR are listed in Tables S4 and S5 and summarized in Figure 2. One-way ANOVA were performed to evaluate the significance of differences among sample sites, however no significant difference was found. Among the targeted ARGs and MGEs in this study, aadE, intl1, Tn916, strA, strB, tetA, and sullI exhibited high detection rates (over $80 \%$ ). For ARGs, strA and strB were the most abundant. Total absolute abundance of ARGs ranged from $1.51 \times 10^{4} \pm 1.49 \times 10^{4}$ copies $/ \mathrm{mL}$ in river water, $7.78 \times 10^{3} \pm 7.13 \times 10^{3} \mathrm{copies} / \mathrm{mL}$ in source water, and $6.91 \times 10^{2} \pm 6.79 \times 10^{2}$ copies $/ \mathrm{mL}$ in finished water. Total relative abundance of ARGs ranged from $3.96 \times 10^{-3} \pm 3.65 \times 10^{-3}$ copies $/ 16 \mathrm{~S}$ rRNA gene in river water, $4.25 \times 10^{-3}$ $\pm 3.84 \times 10^{-3}$ copies $/ 16 \mathrm{~S}$ rRNA gene in source water, and $1.82 \times 10^{-2} \pm 1.81 \times 10^{-2}$ copies/16S rRNA gene in finished water. In terms of total absolute abundance, the highest ARG level was found in Hohhot river water, whereas in terms of total relative abundance, the highest ARG level was found in Zhengzhou finished water. When compared with the previous study, the absolute abundances of sulII, tet $A$, tet $G$, tet $O$, tet $W$, and tet $X$ in river water were, on average, lower than those in Huangpu River [9]. These results suggest that ARGs are prevalent in the river, source, and finished water of the drinking water treatment processes in the Yellow River catchment. Spatial distribution of ARGs and MGEs was not found, and the Bray-Curtis-based principal coordinate analysis (PCoA) of the ARGs did not show geographical clustering (Figure S2).
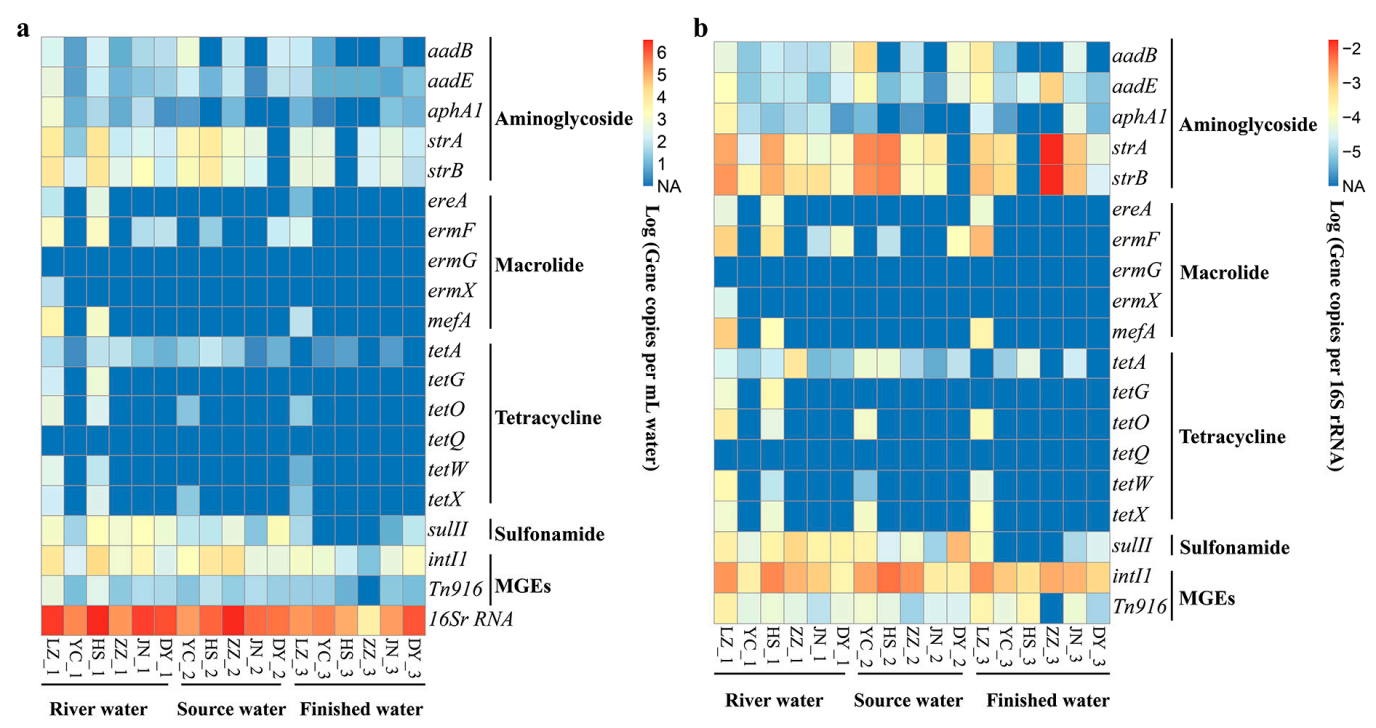

Figure 2. (a) Absolute and (b) relative abundances of the 17 ARGs, two MGEs, and 16s rRNA in water samples. Label under each column denotes sample site name followed by water type (1 is river water, 2 is source water, 3 is finished water).

To clarify the variation of ARGs and MGEs in the drinking water treatment processes, comparisons among river water, source water, and finished water were performed (Figure 3 and Figure S3). Variation in the total absolute abundance of ARGs showed that they decreased with treatment processes. 
On average, the total absolute abundance of ARGs decreased from $1.07 \times 10^{4}$ copies $/ \mathrm{mL}$ in river water to $5.39 \times 10^{3}$ copies $/ \mathrm{mL}$ in source water and $5.99 \times 10^{2}$ copies $/ \mathrm{mL}$ in finished water. In addition, total relative abundance of ARGs increased, on average, from $2.7 \times 10^{-3}$ copies $/ 16 \mathrm{~S} \mathrm{rRNA}$ gene in river water to $3.68 \times 10^{-3}$ copies/16S rRNA gene in source water and $7.43 \times 10^{-3}$ copies/16S rRNA gene in finished water. For MGEs, total absolute abundance decreased, on average, from $1.51 \times 10^{6}$ copies $/ \mathrm{mL}$ in river water to $1.15 \times 10^{6}$ copies $/ \mathrm{mL}$ in source water and $3.19 \times 10^{5}$ copies $/ \mathrm{mL}$ in finished water, whereas total relative abundance remained relatively stable at $1.58 \times 10^{-3}$ copies/16S rRNA gene in river water to $2.15 \times 10^{-3}$ copies/16S rRNA gene in source water and $1.50 \times 10^{-3}$ copies/16S rRNA gene in finished water. The decrease in total absolute abundance of ARGs and MGEs could be explained by the elimination of bacteria during the water treatment processes, especially treated by drinking water treatment plants that have disinfection processes to eliminate them. As for total relative abundance of ARGs and MGEs, no variation trend was observed in this study. This result suggested the possibility that ARGs and MGEs are carried by bacteria that can survive from the water treatment processes, while bacteria did not carry those genes were eliminated more effectively, which caused the proportions of ARGs and MGEs to remain unchanged or even increase. The results are consistent with a previous study which showed bla $a_{\mathrm{TEM}}$, bla $a_{\mathrm{SHV}}$, sullI and cat genes' absolute abundance decreased while the relative abundance increased [15]. To better compare removal effect of two major treatment processes (SSRs and DWTPs), the levels of ARGs removal in the treatment processes are provided in Table 1.

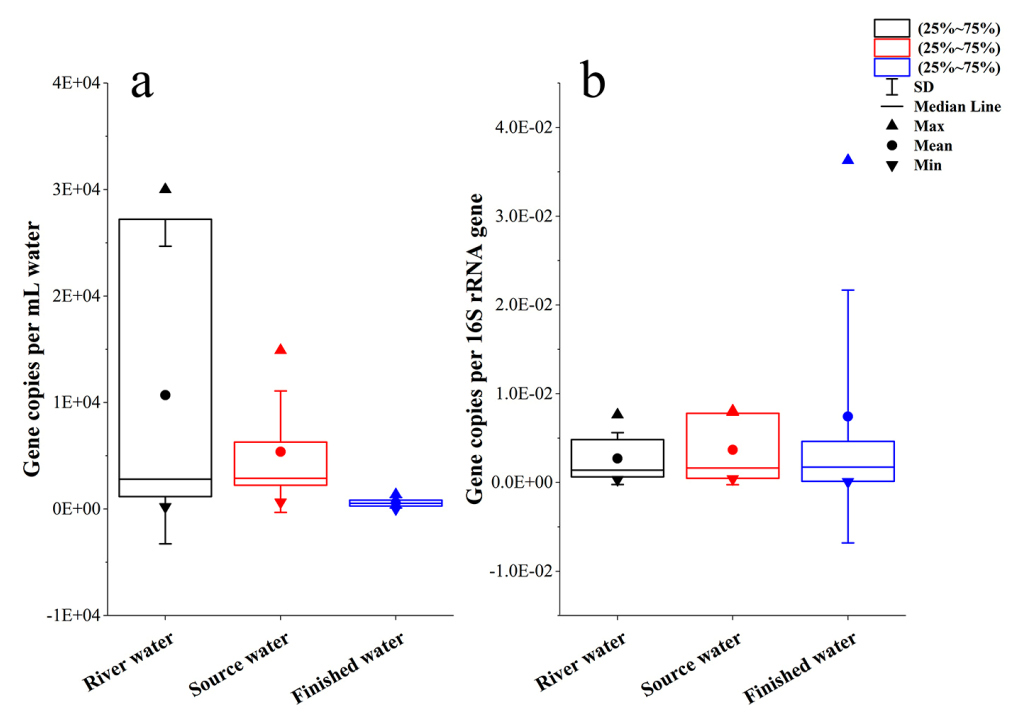

Figure 3. Total absolute (a) and relative (b) abundances of ARGs (copies/mL water) in river, source, and finished water.

SSRs were observed to have different removal of ARGs in different cities. In Yinchuan, only aphA1 was removed at a level of $0.32-\log$, other ARGs include aadB, aadE, $\operatorname{str} A, \operatorname{str} B$, tet $A$, tet $O$, tet X, and sulII increased at the levels range from $-0.45-\log$ to $-2.16-\log$. Similarly, in Zhengzhou, only tet $A$ and sulII were removed at a level of $<1-\log$, while all aminoglycoside resistance genes that were detected increased. Better SSRs removal level of ARGs was observed in Donying, where $\operatorname{aph} A 1, \operatorname{str} A$, and $\operatorname{str} B$ have removal level range from 0.46-log to 2.14-log. In Hohhot and Jinan, SSRs have the removal of all detected ARGs at the levels range from 0.22-log to 3.07-log except tet $A$ increased in Hohhot and $s t r A$ increased in Jinan. SSRs were special treatment process in the Yellow River catchment. With its relatively slow flow rate and sedimentation function, it could be partly compared with sedimentation tank in DWTPs. However, SSRs did not show high removal level like of sedimentation in DWTPs reported in recent study [25]. In Yinchuan, Zhengzhou, and Dongying, total absolute abundance of ARGs increased at levels range from $-0.24-\log$ to $-1.46-\log$ after SSRs treatment, while 16S rRNA 
genes were removed at levels range from 0.29-log to 0.67-log in all SSRs except Zhengzhou. Therefore, the results concerning dissemination of ARGs in SSRs, and whether there were transfer and selection of ARGs in SSRs remain further study.

Table 1. The log removal of ARGs in the treatment processes of six sample cities.

\begin{tabular}{|c|c|c|c|c|c|c|c|c|c|c|c|}
\hline Gene & \multicolumn{5}{|c|}{ SSRs } & \multicolumn{6}{|c|}{ DWTPs } \\
\hline 16S rRNA gene & 0.29 & 0.67 & -1.28 & 0.41 & 0.36 & 1.05 & -0.35 & 0.82 & 2.88 & 0.62 & -0.29 \\
\hline aadE & -1.38 & 1.06 & -1.00 & 0.85 & -0.37 & 0.87 & 1.19 & 0.16 & 1.10 & -0.31 & 0.67 \\
\hline $\operatorname{aph} A 1$ & 0.32 & 1.67 & -0.28 & 1.77 & 0.46 & 1.89 & 0.35 & ND & 1.10 & -1.19 & -1.05 \\
\hline ereA & ND & 2.55 & ND & ND & ND & 0.90 & ND & ND & ND & ND & ND \\
\hline ermF & ND & 1.77 & ND & 1.76 & -0.17 & 0.85 & ND & 1.40 & ND & ND & 2.07 \\
\hline ermG & ND & ND & ND & ND & ND & ND & ND & ND & ND & ND & ND \\
\hline ermX & ND & ND & ND & ND & ND & 1.80 & ND & ND & ND & ND & ND \\
\hline$m e f A$ & ND & 3.07 & ND & ND & ND & 1.78 & ND & ND & ND & ND & ND \\
\hline tet $W$ & ND & 1.91 & ND & ND & ND & 1.54 & ND & ND & ND & ND & ND \\
\hline tet $X$ & -1.34 & 2.38 & ND & ND & ND & 0.86 & 1.34 & ND & ND & ND & ND \\
\hline sulli & -0.45 & 1.35 & 0.25 & 2.03 & -0.54 & 1.40 & 1.97 & 1.94 & 2.65 & 0.37 & 1.48 \\
\hline intI1 & -0.96 & 0.40 & -1.29 & 0.85 & -0.28 & 0.94 & 0.40 & 1.92 & 2.98 & -0.05 & -0.57 \\
\hline $\operatorname{Tn} 916$ & -0.10 & 0.59 & -0.09 & -0.01 & 0.22 & 1.16 & -0.20 & 0.90 & 1.44 & 0.38 & 0.34 \\
\hline Total & -1.46 & 0.30 & -0.24 & 0.82 & -0.39 & 1.30 & 0.87 & 3.08 & 0.81 & -0.06 & 1.00 \\
\hline
\end{tabular}

DWTPs are important constructions designed to enhance drinking water quality. In this study, total absolute abundance of ARGs decreased in all DWTPs at levels range from 0.81-log to 3.08-log, except Jinan, where ARGs concentration increased 0.06-log after DWTPs. Generally, DWTPs showed removal effects of ARGs, which also been provided in previous studies [5,8,25]. In Lanzhou, Yinchuan, Hohhot and Zhengzhou, all detected ARGs decreased at level range from 0.16-log to 3.89-log after DWTPs. However, in Donying, aphA1, strA, strB increased partly because the increasing of 16S rRNA. Total absolute and relative abundances increased in the Jinan finished water. This is noteworthy because the DWTP in Jinan uses BAC as advanced treatment. Previous study has shown that BAC can increase the relative abundance of ARGs and ARB as it aggregates microbes [5,7]. Therefore, our results suggest that BAC may play a key role in affecting ARGs, and its influence on ARGs in drinking water needs further assessment.

The correlations among the relative abundances of ARGs and MGEs are shown in Table S6. Results showed that ereA was significantly correlated with intl1, which also has been shown in a recent study of greenhouse soil [32]. In addition, some of the detected ARGs had significant correlations with transposon Tn916, including one aminoglycoside ARG (aphA1), four macrolide ARGs (ereA, ermF, ermX, and mefA), and three tetracycline ARGs (tetO, tet $W$, and tetX). Intl1 and the Tn916/Tn1545 transposon family contain a variety ARGs, including tetracycline, macrolide, and aminoglycoside resistance genes [33,34]. The correlations between intl1 and Tn916/Tn1545 in this study indicate the potential association with the additional horizontal transfer of ARGs. As MGEs were not eliminated efficiently in the drinking water treatment processes, as shown in Figure S3, the risk of ARG horizontal transfer is worth the attention. 


\subsection{Diversity and Distribution Patterns of Bacteria along Water Treatment}

Based on PCoA analysis, the overall bacterial community structure showed more commonalities in the finished water from all of the cities that were analysed (Figure S4). The Shannon and Simpson diversity indices (Table S7) showed that bacterial community diversity declined after treatment via DWTPs in all of the sample sites, except for Hohhot, but no significant differences were observed between river and source water. The differences in the diversity of the bacterial community between the river and source water was varied, with two showing a slight rise and three demonstrating a decline. In this study, all of the DWTPs applied conventional processes, which include coagulation and sedimentation, sand filtration, and chloramine disinfection except for Jinan which has additional BAC treatment. One of the major function of these processes is to eliminate the microorganisms from water. Among them, chloramine disinfection has strong selection to Proteobacteria. This result is consistent with previous studies that have shown the reduction of bacterial diversity due to selection of chloramine resistance $[17,25]$.

At the phylum level, as shown in Figure S5 and Table S8, Proteobacteria increased considerably in the finished water and became dominant. At the genus level, however, the distribution of bacteria could be divided into four patterns (Figure 4). Bacteria showing A and C pattern distributions, including Mycobacterium, Synechococcus, Planctomycetaceae, Actinobacteria, and Rhodobacter, were dominant both in river and source water, but their proportions decreased in finished water. In contrast, the proportion of bacteria showing B pattern distribution, including Pseudomonas, Massilia, Acinetobacter, Sphingomonas, Methylobacterium, Brevundimonas, and Deinococcus, increased markedly in the finished water and became dominant. The genera exhibiting these different patterns are listed Table S9. Previous metagenomic research has indicated that Proteobacteria are the main antibiotic resistant bacteria in drinking water [17], which may relate to their chlorination resistance [35]. Among the genera that were dominant in the finished water, all were Proteobacteria, except for Deinococcus. In previous drinking water studies, Pseudomonas has been regarded as an opportunistic bacterial pathogen that can spread acquired antibiotic resistance preferentially via vertical transmission [36]. Further studies have also reported that Massilia contains sulfonamide resistance genes [37], Acinetobacter is associated with multi-drug resistance [38], Sphingomonas is positively correlated to ARGs encoding the RND (resistance-nodulation-cell division protein family) transportation system [39], Methylobacterium is resistant to disinfection [40], and Brevundimonas possesses innate resistance to fluoroquinolones [41]. By comparing the distribution of genera (Figure 4) with the distribution of ARGs (Figure 2), a correlation between predominate ARGs (strA and $\operatorname{str} B$ ) and bacterial genera in finished water was observed. As these bacteria are associated with antibiotic resistance, they are of public health concern.

To further prove the correlation between ARGs and bacteria, the co-occurrence patterns between ARGs and bacterial taxa were investigated using network analysis, as shown in Figure 5. Two bacterial genera, Brevundimonas and Methylobacterium, were suggested as the possible hosts of two ARGs ( $\operatorname{str} A$ and $\operatorname{str} B$ ) (Table S10). Notably, these two genera were enriched in the finished water and their proportions were highly increased in the finished water of Zhengzhou. This may explain the increase in the total relative abundance of ARGs in the finished water sample as the $\operatorname{str} A$ and $s \operatorname{tr} B$ ARG subtypes in the finished water of Zhengzhou were dominant. Although Brevundimonas species has rarely been reported as a pathogen causing human infection, it has been isolated in some infection cases [41]. Methylobacterium species has been considered as a serious concern in hospitals due to its contamination of tap water [42]. There has been no report of $\operatorname{str} A$-strB streptomycin-resistance of Brevundimonas and Methylobacterium yet, aminoglycosides were recommended as important treatment of Methylobacterium species infection [43]. However, since $s \operatorname{tr} A$-strB streptomycin-resistance genes widely distribute in bacteria, and strA-strB are often encoded on transposon borne on conjugative plasmid [44], potential aminoglycosides resistance in Brevundimonas and Methylobacterium that is caused by horizonal transfer need to be further studied. 

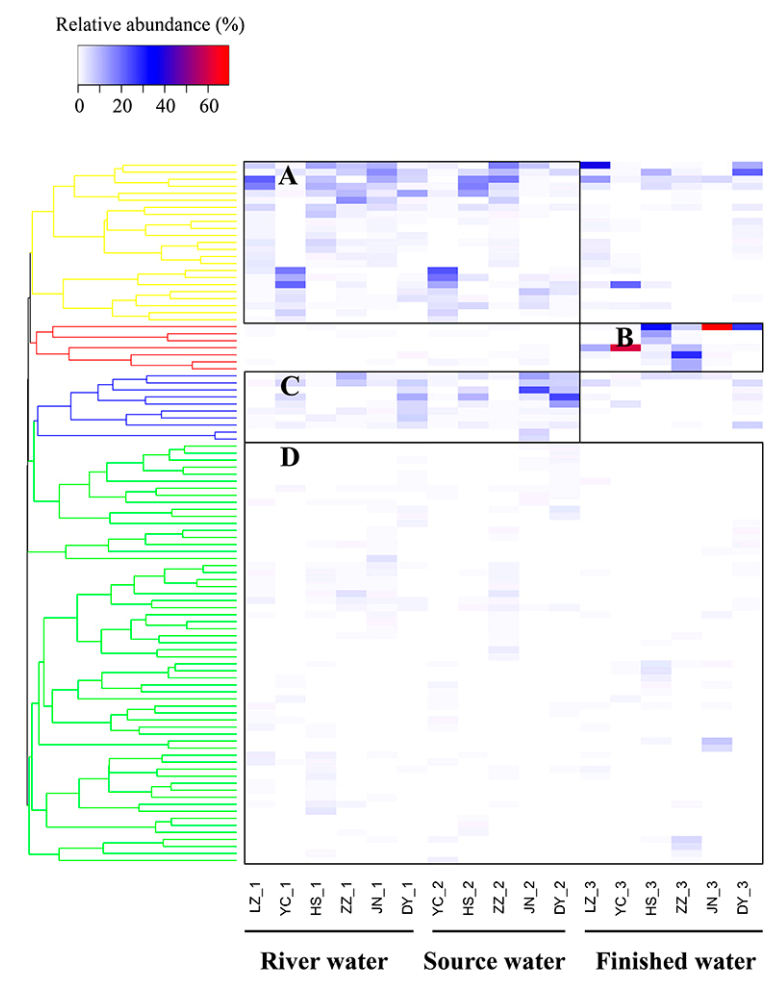

Figure 4. Heatmap of distribution profiles of bacterial genera across different water samples. Each row represents the results of genus percentage by sequencing. Dendrograms for the rows were constructed from the Bray-Curtis dissimilarity distance. Black boxes represent different patterns of genera: (A) widely detected in all water types, dominant in river and source water; (B) highly enriched in finished water, but rarely detected in river and source water; (C) mainly detected in river and source water, but not in finished water; and, (D) relatively low in all water types.

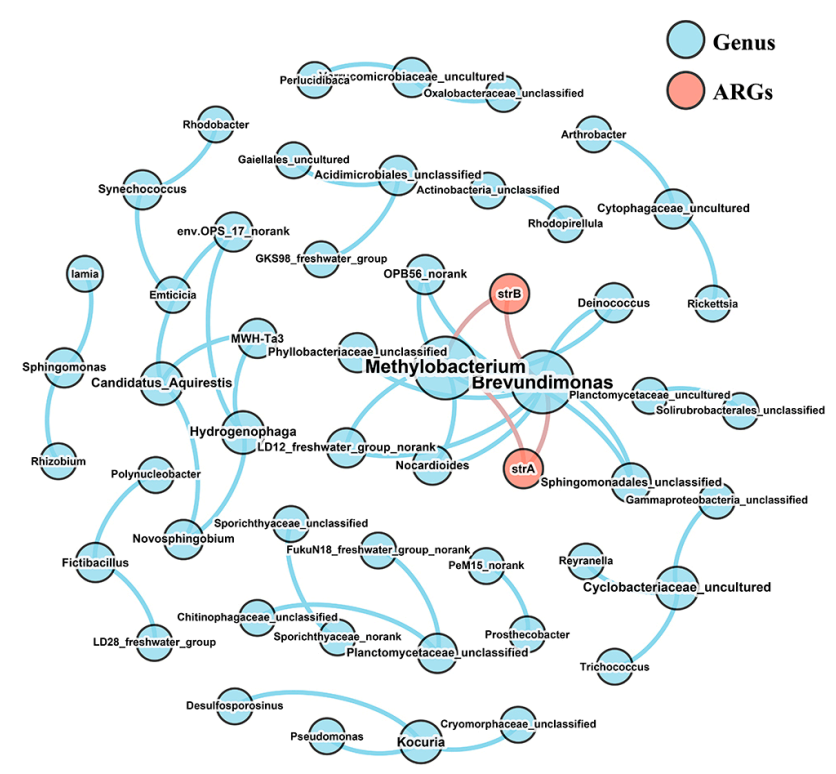

Figure 5. Network analysis revealing the co-occurrence patterns among ARG subtypes and bacteria genera. Nodes are colored according to ARG subtypes. Connection represents correlation. Size of each node is proportional to the number of connections. 


\section{Conclusions}

In this study, variations in 17 ARGs and two MGEs in drinking water treatment processes in the Yellow River catchment were documented by qPCR. At the catchment scale, the absolute abundances of ARGs and MGEs decreased after drinking water treatment, whereas the relative abundances of ARGs and MGEs did not, suggesting the potential risk of ARGs in drinking water. The bacterial community in the drinking water treatment processes was analyzed by sequencing. The distribution of bacterial genera was characterized into four patterns, with two dominant bacterial genera (Brevundimonas and Methylobacterium) found to be associated with two enriched ARGs ( $\operatorname{str} A$ and $\operatorname{str} B$ ) in the finished water. As these two genera are reported to be resistant to disinfection, their high proportion in finished water in the present study confirms the impact of disinfection to antibiotic resistance in drinking water at the catchment scale.

Supplementary Materials: The following are available online at http:/ / www.mdpi.com/2073-4441/10/3/246/s1, Figure S1. Number of ARGs subtypes in 17 water samples; Figure S2. Bray-Curtis-based Principal coordinates analysis of (a) relative and (b) absolute abundance of ARGs in 17 water samples; Figure S3. (A) Total absolute abundance of MGEs (copies/mL water) in river water, source water and finished water. (B) Total relative abundance of MGEs (copies/16S rRNA) in river water, source water and finished water; Figure S4. Bray-Curtis-based Principal coordinates analysis of microbial communities in 17 water samples; Figure S5. Bacteria proportion on phylum level of 17 water samples; Table S1. River water quality parameters; Table S2. PCR primers for the investigated ARGs, MGEs and bacterial 16s rRNA gene; Table S3. Quality control of the real-time qPCR methods for the all target genes; Table S4. Absolute abundances of the 17 ARGs and 2 MGEs (copies/mL water) in water samples; Table S5. Relative abundances of the 18 ARGs and 2 MGEs (gene copies/16S rRNA gene copies) in water samples; Table S6. Correlation of ARGs with MGEs; Table S7. Coverage and diversity indices of bacterial communities by Miseq sequencing; Table S8. Relative abundances of bacterial community compositions grouped by phylum in different water samples. The abundance is presented in terms of the percentage of the targeted phylum in the total sequences of a sample (\%); Table S9. Genera distribution patterns in 17 water samples; Table S10. Genera percentage of bacteria co-occurrence with ARGs.

Acknowledgments: This study was supported by National Natural Science Foundation of China (No. 21437005).

Author Contributions: Yu Zhang conceived and designed the experiments; Jianwei Yu collected water samples; Junying Lu performed the experiments; Junying Lu analyzed the data and wrote the paper. Yu Zhang, Min Yang and Zhe Tian revised the manuscript.

Conflicts of Interest: The authors declare no conflict of interest.

\section{References}

1. Pruden, A.; Pei, R.; Storteboom, H.; Carlson, K.H. Antibiotic resistance genes as emerging contaminants: Studies in northern colorado. Environ. Sci. Technol. 2006, 40, 7445-7450. [CrossRef] [PubMed]

2. Zhang, X.-X.; Zhang, T.; Fang, H.H. Antibiotic resistance genes in water environment. Appl. Microbiol. Biotechnol. 2009, 82, 397-414. [CrossRef] [PubMed]

3. Baquero, F.; Martínez, J.-L.; Cantón, R. Antibiotics and antibiotic resistance in water environments. Curr. Opin. Biotechnol. 2008, 19, 260-265. [CrossRef] [PubMed]

4. Li, D.; Yu, T.; Zhang, Y.; Yang, M.; Li, Z.; Liu, M.; Qi, R. Antibiotic resistance characteristics of environmental bacteria from an oxytetracycline production wastewater treatment plant and the receiving river. Appl. Environ. Microbiol. 2010, 76, 3444-3451. [CrossRef] [PubMed]

5. Xu, L.; Ouyang, W.; Qian, Y.; Su, C.; Su, J.; Chen, H. High-throughput profiling of antibiotic resistance genes in drinking water treatment plants and distribution systems. Environ. Pollut. 2016, 213, 119-126. [CrossRef] [PubMed]

6. Huerta, B.; Marti, E.; Gros, M.; López, P.; Pompêo, M.; Armengol, J.; Barceló, D.; Balcázar, J.L.; Rodríguez-Mozaz, S.; Marcé, R. Exploring the links between antibiotic occurrence, antibiotic resistance, and bacterial communities in water supply reservoirs. Sci. Total Environ. 2013, 456, 161-170. [CrossRef] [PubMed]

7. Bai, X.; Ma, X.; Xu, F.; Li, J.; Zhang, H.; Xiao, X. The drinking water treatment process as a potential source of affecting the bacterial antibiotic resistance. Sci. Total Environ. 2015, 533, 24-31. [CrossRef] [PubMed] 
8. Guo, X.; Li, J.; Yang, F.; Yang, J.; Yin, D. Prevalence of sulfonamide and tetracycline resistance genes in drinking water treatment plants in the yangtze river delta, china. Sci. Total Environ. 2014, 493, 626-631. [CrossRef] [PubMed]

9. Jiang, L.; Hu, X.; Xu, T.; Zhang, H.; Sheng, D.; Yin, D. Prevalence of antibiotic resistance genes and their relationship with antibiotics in the huangpu river and the drinking water sources, shanghai, china. Sci. Total Environ. 2013, 458-460, 267-272. [CrossRef] [PubMed]

10. Schwartz, T.; Kohnen, W.; Jansen, B.; Obst, U. Detection of antibiotic-resistant bacteria and their resistance genes in wastewater, surface water, and drinking water biofilms. FEMS Microbiol. Ecol. 2003, 43, 325-335. [CrossRef] [PubMed]

11. Coleman, B.L.; Louie, M.; Salvadori, M.I.; McEwen, S.A.; Neumann, N.; Sibley, K.; Irwin, R.J.; Jamieson, F.B.; Daignault, D.; Majury, A.; et al. Contamination of canadian private drinking water sources with antimicrobial resistant Escherichia coli. Water Res. 2013, 47, 3026-3036. [CrossRef] [PubMed]

12. Bergeron, S.; Boopathy, R.; Nathaniel, R.; Corbin, A.; LaFleur, G. Presence of antibiotic resistant bacteria and antibiotic resistance genes in raw source water and treated drinking water. Int. Biodeterior. Biodegrad. 2015, 102, 370-374. [CrossRef]

13. Fernando, D.M.; Tun, H.M.; Poole, J.; Patidar, R.; Li, R.; Mi, R.; Amarawansha, G.E.; Fernando, W.G.; Khafipour, E.; Farenhorst, A.; et al. Detection of antibiotic resistance genes in source and drinking water samples from a first nations community in canada. Appl. Environ. Microbiol. 2016, 82, 4767-4775. [CrossRef] [PubMed]

14. Egervarn, M.; Englund, S.; Ljunge, M.; Wiberg, C.; Finn, M.; Lindblad, M.; Borjesson, S. Unexpected common occurrence of transferable extended spectrum cephalosporinase-producing Escherichia coil in swedish surface waters used for drinking water supply. Sci. Total Environ. 2017, 587, 466-472. [CrossRef] [PubMed]

15. Xi, C.; Zhang, Y.; Marrs, C.F.; Ye, W.; Simon, C.; Foxman, B.; Nriagu, J. Prevalence of antibiotic resistance in drinking water treatment and distribution systems. Appl. Environ. Microbiol. 2009, 75, 5714-5718. [CrossRef] [PubMed]

16. Farkas, A.; Butiuc-Keul, A.; Ciataras, D.; Neamtu, C.; Craciunas, C.; Podar, D.; Dragan-Bularda, M. Microbiological contamination and resistance genes in biofilms occurring during the drinking water treatment process. Sci. Total Environ. 2013, 443, 932-938. [CrossRef] [PubMed]

17. Shi, P.; Jia, S.; Zhang, X.-X.; Zhang, T.; Cheng, S.; Li, A. Metagenomic insights into chlorination effects on microbial antibiotic resistance in drinking water. Water Res. 2013, 47, 111-120. [CrossRef] [PubMed]

18. Zhang, S.; Lin, W.; Yu, X. Effects of full-scale advanced water treatment on antibiotic resistance genes in the yangtze delta area in china. FEMS Microbiol. Ecol. 2016, 92. [CrossRef] [PubMed]

19. Xu, W.; Zhang, G.; Zou, S.; Ling, Z.; Wang, G.; Yan, W. A preliminary investigation on the occurrence and distribution of antibiotics in the Yellow River and its tributaries, china. Water Environ. Res. 2009, 81, 248-254. [CrossRef] [PubMed]

20. Zhou, L.J.; Ying, G.G.; Zhao, J.L.; Yang, J.F.; Wang, L.; Yang, B.; Liu, S. Trends in the occurrence of human and veterinary antibiotics in the sediments of the Yellow River, Hai river and liao river in northern china. Environ. Pollut. 2011, 159, 1877-1885. [CrossRef] [PubMed]

21. Xu, Y.; Guo, C.; Luo, Y.; Lv, J.; Zhang, Y.; Lin, H.; Wang, L.; Xu, J. Occurrence and distribution of antibiotics, antibiotic resistance genes in the urban rivers in beijing, china. Environ. Pollut. 2016, 213, 833-840. [CrossRef] [PubMed]

22. Li, X.; Yu, J.; Guo, Q.; Su, M.; Liu, T.; Yang, M.; Zhao, Y. Source-water odor during winter in the yellow river area of china: Occurrence and diagnosis. Environ. Pollut. 2016, 218, 252-258. [CrossRef] [PubMed]

23. Tian, Z.; Zhang, Y.; Yu, B.; Yang, M. Changes of resistome, mobilome and potential hosts of antibiotic resistance genes during the transformation of anaerobic digestion from mesophilic to thermophilic. Water Res. 2016, 98, 261-269. [CrossRef] [PubMed]

24. Pei, R.; Kim, S.-C.; Carlson, K.H.; Pruden, A. Effect of river landscape on the sediment concentrations of antibiotics and corresponding antibiotic resistance genes (arg). Water Res. 2006, 40, 2427-2435. [CrossRef] [PubMed]

25. Su, H.C.; Liu, Y.S.; Pan, C.G.; Chen, J.; He, L.Y.; Ying, G.G. Persistence of antibiotic resistance genes and bacterial community changes in drinking water treatment system: From drinking water source to tap water. Sci. Total Environ. 2017, 616-617, 453-461. [CrossRef] [PubMed] 
26. Caporaso, J.G.; Lauber, C.L.; Walters, W.A.; Berg-Lyons, D.; Lozupone, C.A.; Turnbaugh, P.J.; Fierer, N.; Knight, R. Global patterns of $16 \mathrm{~s}$ rrna diversity at a depth of millions of sequences per sample. Proc. Natl. Acad. Sci. USA 2011, 108, 4516-4522. [CrossRef] [PubMed]

27. Li, B.; Yang, Y.; Ma, L.; Ju, F.; Guo, F.; Tiedje, J.M.; Zhang, T. Metagenomic and network analysis reveal wide distribution and co-occurrence of environmental antibiotic resistance genes. ISME J. 2015, 9, 2490-2502. [CrossRef] [PubMed]

28. Deng, Y.; Jiang, Y.-H.; Yang, Y.; He, Z.; Luo, F.; Zhou, J. Molecular ecological network analyses. BMC Bioinform. 2012, 13, 113. [CrossRef] [PubMed]

29. Deng, Y.; Zhang, P.; Qin, Y.; Tu, Q.; Yang, Y.; He, Z.; Schadt, C.W.; Zhou, J. Network succession reveals the importance of competition in response to emulsified vegetable oil amendment for uranium bioremediation. Environ. Microbiol. 2016, 18, 205-218. [CrossRef] [PubMed]

30. Kolde, R. Pheatmap: Pretty Heatmaps. R Package Version 1.0.8. 2015. Available online: http:/ /CRAN.Rproject.org $/$ package=pheatmap (accessed on 27 February 2018).

31. Oksanen, J.; Kindt, R.; Legendre, P.; O’Hara, B.; Stevens, M.H.H.; Oksanen, M.J.; Suggests, M. The vegan package. Community Ecol. Package 2007, 10, 631-637.

32. Li, J.; Xin, Z.; Zhang, Y.; Chen, J.; Yan, J.; Li, H.; Hu, H. Long-term manure application increased the levels of antibiotics and antibiotic resistance genes in a greenhouse soil. Appl. Soil Ecol. 2017, 121, 193-200. [CrossRef]

33. Santoro, F.; Vianna, M.E.; Roberts, A.P. Variation on a theme; an overview of the $\operatorname{tn} 916 / \operatorname{tn} 1545$ family of mobile genetic elements in the oral and nasopharyngeal streptococci. Front. Microbiol. 2014, 5, 535. [CrossRef] [PubMed]

34. Roberts, A.P.; Mullany, P. Tn916-like genetic elements: A diverse group of modular mobile elements conferring antibiotic resistance. FEMS Microbiol. Rev. 2011, 35, 856-871. [CrossRef] [PubMed]

35. Mathieu, L.; Bouteleux, C.; Fass, S.; Angel, E.; Block, J. Reversible shift in the $\alpha$-, $\beta$-and $\gamma$-proteobacteria populations of drinking water biofilms during discontinuous chlorination. Water Res. 2009, 43, 3375-3386. [CrossRef] [PubMed]

36. Vaz-Moreira, I.; Nunes, O.C.; Manaia, C.M. Diversity and antibiotic resistance in Pseudomonas spp. from drinking water. Sci. Total Environ. 2012, 426, 366-374. [CrossRef] [PubMed]

37. Wang, N.; Yang, X.; Jiao, S.; Zhang, J.; Ye, B.; Gao, S. Sulfonamide-resistant bacteria and their resistance genes in soils fertilized with manures from jiangsu province, southeastern china. PLoS ONE 2014, 9, e112626. [CrossRef] [PubMed]

38. Zhang, Y.; Marrs, C.F.; Simon, C.; Xi, C. Wastewater treatment contributes to selective increase of antibiotic resistance among Acinetobacter spp. Sci. Total Environ. 2009, 407, 3702-3706. [CrossRef] [PubMed]

39. Jia, S.; Shi, P.; Hu, Q.; Li, B.; Zhang, T.; Zhang, X.-X. Bacterial community shift drives antibiotic resistance promotion during drinking water chlorination. Environ. Sci. Technol. 2015, 49, 12271-12279. [CrossRef] [PubMed]

40. Simões, L.C.; Simoes, M.; Vieira, M.J. Influence of the diversity of bacterial isolates from drinking water on resistance of biofilms to disinfection. Appl. Environ. Microbiol. 2010, 76, 6673-6679. [CrossRef] [PubMed]

41. Han, X.Y.; Andrade, R.A. Brevundimonas diminuta infections and its resistance to fluoroquinolones. J. Antimicrob. Chemother. 2005, 55, 853-859. [CrossRef] [PubMed]

42. Furuhata, K.; Kato, Y.; Goto, K.; Hara, M.; Yoshida, S.-I.; Fukuyama, M. Isolation and identification of methylobacterium species from the tap water in hospitals in japan and their antibiotic susceptibility. Microbiol. Immunol. 2006, 50, 11-17. [CrossRef] [PubMed]

43. Lee, C.-H.; Tang, Y.-F.; Liu, J.-W. Underdiagnosis of urinary tract infection caused by methylobacterium species with current standard processing of urine culture and its clinical implications. J. Med. Microbiol. 2004, 53, 755-759. [CrossRef] [PubMed]

44. Sundin, G.W.; Bender, C.L. Dissemination of the stra-strb streptomycin-resistance genes among commensal and pathogenic bacteria from humans, animals, and plants. Mol. Ecol. 1996, 5, 133-143. [CrossRef] [PubMed]

(C) 2018 by the authors. Licensee MDPI, Basel, Switzerland. This article is an open access article distributed under the terms and conditions of the Creative Commons Attribution (CC BY) license (http:/ / creativecommons.org/licenses/by/4.0/). 